\title{
VERTEBROBASILAR BLOOD FLOW IN GERIATRIC PATIENTS WITH HIP FRACTURES
}

\author{
Ekrem Aydin ${ }^{1}$ \\ Correspondence: efaruk92@gmail.com \\ ${ }^{I}$ Department of orthopedics and traumatology of Anadolu Hospital Bursa, Turkey
}

\section{Article History:}

Received: December 29, 2019

Accepted: September 29, 2020

Published: January 1, 2021

\section{Cite this as:}

Aydin E.Vertebrobasilar blood

flow in geriatric patients with hip

fractures Publisher. Malang

Neurology Journal; 2021.7:20 -

23.

http://dx.doi.org/10.21776/ub.mnj 2021.007.01.5

\section{ABSTRACT}

Background: Falls constitute a problem especially in individuals aged above 70 years in terms of fracture formation. Considering the etiology of falling, insufficiency of the blood flow which feeds the balance center in the brain may cause postural hypotension and vertigo and may lead to falling.

Objective: In this study, we emphasized the importance of evaluating vertebrobasilar blood flow in the etiology of fractures in the elderly.

Methods: This study was executed on 48 patients aged 70 years and older ( 28 females, 20 males, mean age 80.45), who were presented to the emergency department of Dumlupinar University Evliya Çelebi Training and Research Hospital with hip fractures resulting from a simple fall around where they live, diagnosed with hip fractures and treated via joint prostheses or different internal and external fixation methods. After the stabilization of the patients' postoperative fractures, the carotid artery lumen and blood flow, vertebral arterial lumen, diameter and blood flow were examined via doppler ultrasonography. The control group was comprised of 48 patients aged 70 years and older (26 females, 22 males, mean age 75.52 years) who were presented to the Polyclinic of Neurology for routine examination and had no falling and fracture history, and the carotid artery and vertebral artery examination of this group was also performed by the same radiologist via doppler ultrasonography

Results: In individuals aged above 70 years, temporary cerebral blood flow disorders are more severe in those with vertebrobasilar insufficiency. This study was conducted between 2015-2016 on 48 patients aged 70 years and older ( 28 females and 20 males), who were presented to the emergency department of Dumlupınar University Faculty of Medicine Training and Research Hospital and hospitalized due to hip fractures; the control group was comprised of 48 patients within the same age group, who were presented to the Polyclinic of Neurology with different complaints (26 females and 22 males).The vertebral arterial diameters and flow velocities of the patients were assessed via Doppler USG.

Conclusion: The vertebral arterial diameters and flow velocities were found statistically lower in the patient group with fracture formation resulting from falling. We recommend taking precautions against the risk of falling in patients aged above 70 years who are found to have a flow decrease through carotid artery doppler USG at certain intervals.

Keywords: Hip fracture, falling, vertebrobasilar insufficiency

\section{Introduction}

Falls and resulting hip fractures increase with the advancing age, especially in those at 70 years of age and above. Most of the falls occur in consequence of postural imbalance and stroke $\mathrm{e}^{1,2,3,4}$ Visual, vestibular, proprioceptive and mechanoceptive systems have effects on postural balance ${ }_{4,5,6,7}$ Postural hypotension, insufficiency in the veins feeding the balance center, associatively vertigo play a key role in the falling etiologies of the elderly and accordingly in the indirect etiologies of hip fractures ${ }^{7,8}$ Studies show that $1 / 3$ of the elderly aged 70 years and older are exposed to serious falls at least once a year. ${ }^{9,10}$

Approximately $30 \%$ of the elderly aged 70 years and older have vertigo. It was discovered in a study that a temporary decrease in the arterial blood pressure by $10 \%$ caused a temporary decrease in the cerebral blood flow by $60 \%^{3}$ The expectation that such a temporary cerebral flow disorder will be more severe in geriatric patients with vertebrobasilar insufficiency is quite common.

Dynamic and structural evaluation of the carotid and vertebral arteries through doppler ultrasonography is a practical and noninvasive method. ${ }^{2}$ In our study, the statistical relationship between vertebrobasilar flow insufficiencies and hip fractures resulting from falling was researched in patients aged 70 years and older with hip fractures in comparison with the control group consisting of the patients within the same age group, which was independent of the other falling etiologies.

\section{Methods}

This study was executed on 48 patients aged 70 years and older (28 females, 20 males, mean age 80.45), who were presented to the emergency department of Dumlupinar University Evliya Çelebi Training and Research Hospital 
with hip fractures resulting from a simple fall around where they live, diagnosed with hip fractures and treated via joint prostheses or different internal and external fixation methods. After the stabilization of the patients' postoperative fractures, the carotid artery lumen and blood flow, vertebral arterial lumen, diameter and blood flow were examined via doppler ultrasonography in the period when the mobilization of the patient did not lead to a contraindication, before discharge.

Previously existing heart failure, balance and blood pressure problems of the patients were investigated. All the patients were examined via ultrasonography by the same radiologist. During the evaluation, in the diametrical measurement of the vertebral arteries, values below $2 \mathrm{~mm}$ in each vertebral artery, values below $4 \mathrm{~mm}$ in total, values below $200 \mathrm{ml} / \mathrm{min}$ in total in flow measurement and backflow were considered in favor of insufficiency.

The control group was comprised of 48 patients aged 70 years and older (26 females, 22 males, mean age 75.52 years) who were presented to the Polyclinic of Neurology for routine examination and had no falling and fracture history, and the carotid artery and vertebral artery examination of this group was also performed by the same radiologist via doppler ultrasonography.
For the description of the demographic characteristics related to the participants of the study, descriptive statistical analysis techniques were used; the independent group t-test from parametric tests was used in the paired group comparisons including continuous variables and the "ChiSquare Test" was used in the paired group comparisons including categorical variables. The alpha value, which is the value of significance, was considered as .05. All statistical analyses were analyzed on SPSS 22.00.

\section{Results}

The study group was comprised of 48 people and the control group was comprised of 47 people; $28(58.3 \%)$ people in the study group were females and $20(41.7 \%)$ were males, and $26(55.3 \%)$ people in the control group were females, $21(44.7 \%)$ were males. There was no significant difference between the study and control groups in terms of male and female ratios $(\mathrm{X} 2(1, \mathrm{n}=95)=.088$, $\mathrm{p}>.05)$. The mean age of the study group was $80.46( \pm 4.32)$ and the mean age of the control group was $77.13( \pm 4.31)$ (Table 1).

Table 1. Demographic characteristics of the participants of the study

\begin{tabular}{|c|c|c|c|c|c|c|c|c|}
\hline & & \multicolumn{4}{|c|}{ Gender } & & & \multirow[b]{3}{*}{$\mathbf{p}$} \\
\hline & & \multicolumn{2}{|c|}{ Female } & \multicolumn{2}{|r|}{ Male } & \multirow[b]{2}{*}{ df } & \multirow[b]{2}{*}{$\mathbf{X}^{2}$} & \\
\hline & & $\mathbf{n}$ & $\%$ & $\mathbf{n}$ & $\%$ & & & \\
\hline \multirow{2}{*}{ Group } & Study Group & 28 & 58.3 & 20 & 41.7 & \multirow{2}{*}{1} & \multirow{2}{*}{.088} & \multirow{2}{*}{.767} \\
\hline & Control Group & 26 & 55.3 & 21 & 44.7 & & & \\
\hline & Group & $\mathbf{n}$ & & & Standar Deviation & df & $\mathbf{T}$ & $\mathbf{p}$ \\
\hline \multirow[t]{2}{*}{ Age } & Study Group & 48 & & & 4.32 & \multirow{2}{*}{93} & \multirow{2}{*}{3.760} & \multirow{2}{*}{.000} \\
\hline & Control Group & 47 & & & 4.31 & & & \\
\hline
\end{tabular}

Table 2. Comparison of total vertebral flow velocities of study and control groups

\begin{tabular}{lccccccc}
\hline \multicolumn{2}{c}{ Group } & n & Mean & Standar Deviation & t & Sd & p \\
\hline $\begin{array}{l}\text { total } \\
\text { vertebral } \\
\begin{array}{l}\text { artery } \\
\text { volume }\end{array}\end{array}$ & Study Group & 48 & 240.83 & 56.14 & & & \\
\cline { 2 - 5 } & Control Group & 47 & 340.26 & 90.72 & & 76.444 & .000 \\
\hline
\end{tabular}

Table 3. Comparison of carotid artery disease in study and control groups

\begin{tabular}{|c|c|c|c|c|c|c|c|c|}
\hline & & \multicolumn{4}{|c|}{ Carotid artery disease } & \multirow[b]{3}{*}{ df } & & \multirow[b]{3}{*}{$\mathbf{p}$} \\
\hline & & \multicolumn{2}{|c|}{ No } & \multicolumn{2}{|c|}{ Yes } & & \multirow[b]{2}{*}{$\mathbf{X}^{2}$} & \\
\hline & & $\mathrm{n}$ & $\%$ & $\mathbf{n}$ & $\%$ & & & \\
\hline \multirow[b]{2}{*}{ Group } & Study Group & 14 & 29.2 & 34 & 70.8 & \multirow[b]{2}{*}{1} & \multirow[b]{2}{*}{8.902} & \multirow[b]{2}{*}{0.003} \\
\hline & $\begin{array}{l}\text { Control } \\
\text { Group }\end{array}$ & 28 & 59.6 & 19 & 40.4 & & & \\
\hline
\end{tabular}

Table 4. Comparison of right and left vertebral arterial diameters of study and control groups

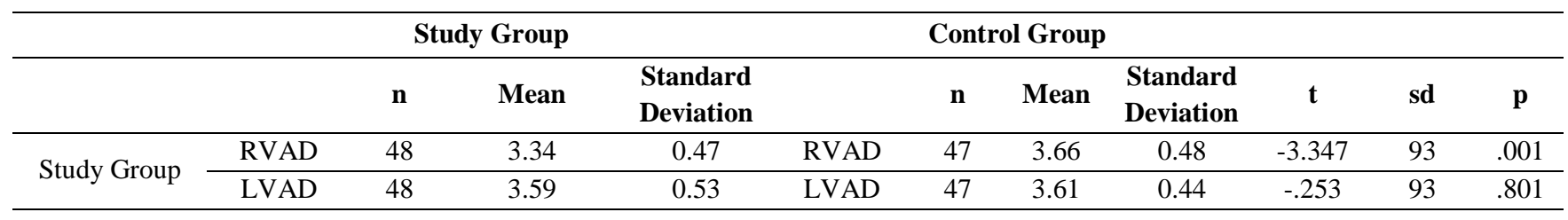

RVAD: Right vertebral arterial inside diameter

LVAD: Left vertebral arterial inside diameter 
While the mean total flow velocity of the vertebral artery was found as $240.83( \pm 56.14)$ in the study group, the mean total flow velocity was $340.36( \pm 90.72)$ in the control group. The total flow velocity of the vertebral artery of the study group was lower than that of the control group, which was at a significant level $(\mathrm{t}(76.444)=-6.408, \mathrm{p}<.05)($ Table 2).

While the number of people with carotid artery disease was $34(70.8 \%)$ in the study group, it was $19(40.4 \%)$ in the control group. Carotid artery disease was significantly higher in the study group than the control group, which was at a significant level $(\mathrm{X} 2(1, \mathrm{n}=95)=8.902, \mathrm{p}<.05)$ (Table 3$)$.

The mean vertebral arterial diameter was obtained as right $3.34 \mathrm{~mm}( \pm 0.47)$ left $3.59 \mathrm{~mm}( \pm 0.53)$ in the study group and right $3.66 \mathrm{~mm}( \pm 0.48)$ left $3.61 \mathrm{~mm}( \pm 0.44)$ in the control group. These values are above $2 \mathrm{~mm}$, which is considered as the limit of stenosis.

The reason why no significant arterial stenosis was detected in our patients with vertebral artery flow insufficiency was attributed to the fact that the flow did not only depend on the lumen diameter but other factors such as heart failure were also important. However, the right vertebral arterial diameter in the study group was significantly lower than that of the control group $(\mathrm{t}(93)=-3.347, \mathrm{p}<.05)$ (Table 4).

\section{Discussion}

In the advanced age group, hip fractures may occur for many reasons. ${ }^{1,2,3,4,5,6}$ These fractures mostly lead to mortality and morbidity. Causes of the increase in the risk of falling have been researched for a long time. Among them, asymmetric vestibular functions and balance problems come into prominence. Visual problems are also included. ${ }^{3,4}$ Studies show that falls and resulting fractures can be reduced with precautions decreasing falls independently from risk factors. ${ }^{4,5}$

In literature reported the increasing effect of postural disorders, especially excessive kyphosis on falls alone or together with balance disorders. Authors keep postural hypotension responsible for hip fractures resulting from falls. ${ }^{9,10}$ Vertigo is especially one of the important problems of patients aged seventy years or older. Vertigo is observed in $30 \%$ of nursery patients aged 70 years and older. In a UK-based research, a $10 \%$ decrease in the orthostatic systolic blood pressure is reported to cause a $60 \%$ decrease in the cerebral blood flow. ${ }^{4}$

Whether the cerebral blood flow, especially posterior cerebral and cerebellar feeding is adequate has a great effect on balance and falls together with visual functions. If each vertebral artery has a diameter less than $2 \mathrm{~mm}$ and the total flow is less than $200 \mathrm{ml} / \mathrm{min}$, then it is pathological. Flow direction should also be upwards. ${ }^{3,6}$

It was concluded in our study that vertebral arterial diameters and vertebral arterial blood flow velocities were statistically and significantly lower in the study group compared to the control group and vertebral artery insufficiency affects the balance system and indirectly cause falls and hip fractures. In addition, according to our results, there is a significant relationship between carotid artery pathologies and vertebral arterial pathologies. Authors emphasizes that it is important to reduce the mechanic obstacles against the exercise programs for balance and flexibility and in living environments. ${ }^{4,7}$ Due to the possibility that vertebral artery insufficiency may lead to falls in people aged 70 years and older, vertebral arterial doppler USG, which is an risk-free and noninvasive method, should be applied in routine check-ups; if vertebrobasilar artery insufficiency is detected, obstacles around the elderly causing falls should be eliminated as much as possible due to the risk of falling in addition to the related medical treatments, and holding equipment should be placed in the areas important for the life activities of the elderly such as restrooms and bathrooms.

\section{Conclusion}

By detecting the vertebrobasilar insufficiency via noninvasive, easy and practical methods such as doppler USG applied to the elderly at certain intervals, taking the necessary precautions to prevent the elderly from falling and seeking treatment, it will be possible to decrease the risk of falling, reduce the rates of mortality and morbidity; thus, contribution will be made to the national economy.

\section{Acknowledgement .}

The researcher would like to thank to Dumlupinar Universty Management and Neurology Clinic.

\section{References}

1. Soleimani R, Jalali MM, Mirbolook AR. Predictors of fear of falling among Iranian older adults with hip fracture and controls Clinical gerontologist; 2019. 19. DOI: 10.1080/07317115.2019.1704958

2. Eibling D. Balance disorders in older adults. Clinics in Geriatric Medicine; 2018. 34(2):175-181.

DOI: 10.1016/j.cger.2018.01.002

3. Santy-Tomlinson J, et al. Falls and secondary fracture prevention. Fragility Fracture Nursing. Springer, Cham; 2018. 27-40. DO : 10.1007/978-3-319-766812_3

4. Byun $\mathrm{H}$, et al. Increased risk of benign paroxysmal positional vertigo in osteoporosis: a nationwide population-based cohort study. Scientific Reports; 2019. 9(1):1-8. DOI: 10.1038/s41598-019-39830-x

5. Jordan DR, Islamiyah WR, Pyaritno JH. Profile of type 2 diabetes mellitus in acute thrombotic stroke in neurology department at dr. Soetomo General Hospital. Malang Neurology Journal; 2019. 5:80-85. DOI: 10.21776/ub.mnj.2019.005.2.6

6. Yurdakul S, Aytekin S. Doppler ultrasaund imaging of the carotid and vertebral arteries. Arch Turk Soc Cardiol; 2011. 39:508-517.

DO : $10.5543 /$ tkda.2011.01588

7. Setiadi QH, Harahap HS, Indrayana Y. The correlation of waist hip ratio to ischemic stroke probability of population in Sekarbela Mataram. Malang Neurology Journal; 2017. 4(1):1-6. DOI: 10.21776/ub.mnj.2018.004.01.1 
8. Amin Hanjani, Sepideh et al. Hypoperfusion syptoms poorly predict hemodynamic compromyse and stroke risk in vertebrobasiler disease. Stroke; 2019. 50(2):495-497.

DOI:10.1161/Strokeaha.118.023101stroke.2019;50:49 5-497

9. Aydin E, Dulgeroglu TC, Metineren H. Bilateral simultaneous intertrochanteric fractures of femur without major trauma. Int Med Case Rep J; 2015. 8:137-9. PMID: 26170725

10. Dewi R, Dewi Kartikawati N, Sri A. Factors affecting the knowledge about stroke risks and early symptoms in emergency department East Java, Indonesia. Malang Neurology Journal; 2020. 6(1). DOI: 10.21776/ub.mnj.2020.006.01.3 